
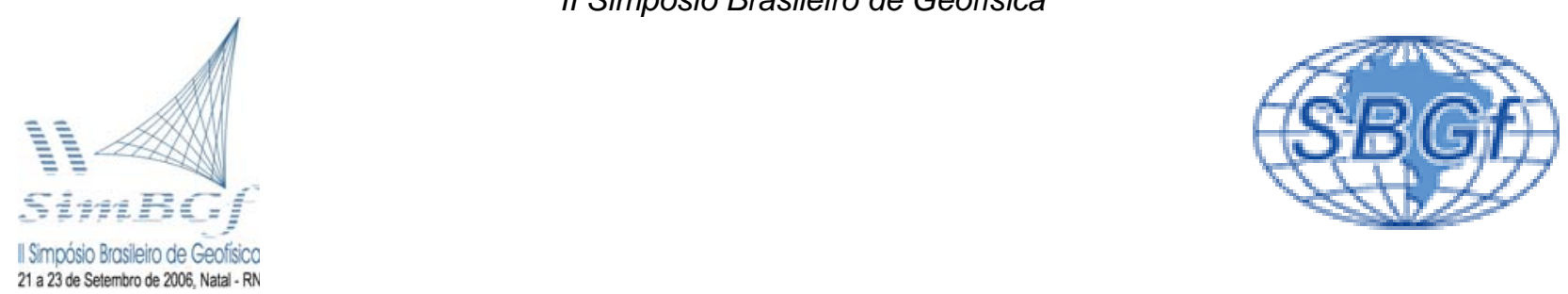

\title{
Integração de ferramentas geofísicas como metodologia rasa precisa para o diagnóstico geoambiental em bacias sedimentares recentes-Estudo de caso
}

Soares, M. J. S., Takayama, P. - BRAIN Tecnologia.

Copyright 2006, SBGf - Sociedade Brasileira de Geofísica

Este texto foi preparado para a apresentação no II Simpósio de Geofísica da Sociedade Brasileira de Geofísica, Natal, 21-23 de setembro de 2006. Seu conteúdo foi revisado pela Comissão Tecno-científica do II SR-SBGf mas não necessariamente representa a opinião da SBGf ou de seus associados. E proibida a reprodução total ou parcial deste material para propósitos comerciais sem prévia autorização da SBGf.

\section{Resumo}

O presente trabalho apresenta a metodologia utilizada pela Brain Tecnologia (2006) para diagnóstico em área impactada por hidrocarboneto. Para tal foram utilizadas as técnicas GPR (Ground Penetrating Radar) 2D e 3D e SEVME (Sondagem Elétrica Vertical Multieletrodo) balizadas por um plano de sondagem detalhado para a definição do arcabouço geológico da região para avaliação da área impactada por hidrocarbonetos. A integração das ferramentas geofísicas apresenta-se como uma metodologia eficiente para a avaliação de impacto ambiental causado por acidentes envolvendo hidrocarbonetos e/ou produtos químicos.

\section{Introdução}

Com a crescente preocupação em diagnosticar e delimitar áreas impactadas, objeto de possíveis sanções econômicas e penais, grandes volumes de serviço e dinheiro têm se despedido para o estudo destas áreas. Baseado nestes fatos e com a premissa de uma maior eficiência para estudos desta natureza, o presente trabalho vem apresentar uma sistemática de diagnóstico, a um custo razoável e com maior eficiência para a delimitação de tais áreas.

A área em questão é um antigo depósito de resíduos oleosos, situada numa região que sofre com um ativo regime pluviométrico. Em função desta configuração ambiental procurou-se avaliar o impacto, local e nas regiões adjacentes, provocado por esta variação hidrológica.

A geologia local é composta por formações arenosas características de ambientes fluviais, dispostas em ciclos sedimentares que apresentam padrões estratificados típicos de variações cíclicas de curta duração de caráter transgressivos e regressivos.

Os depósitos sedimentares compõem-se por sedimentos siliciclásticos avermelhados que incluem arenitos feldspáticos, caulínicos, quartzo-arenitos, quartzograuvacas e brechas intraformacionais, interpretados como depósitos de ambiente flúvio-lacustre. Ocorrem também, paleossolos desenvolvidos nos arenitos, caracterizados pelo aspecto mosqueado, gretas de contração profundas e abundantes traços de raízes.

Na sucessão inferior desta identifica-se a Formação Alter do Chão, característica por apresentar rochas friáveis, pouco coesas, intercaladas por rochas mais endurecidas e de crostas lateríticas e/ou "linhas-de-pedra" que são responsáveis pela preservação tabular do relevo.

\section{Metodologia}

O presente trabalho apresentou as seguintes etapas para a execução do diagnóstico geoambiental:

(1) Levantamento Geofísico: constituído pelos levantamentos GPR 2D, 3D e Sondagem Elétrica Vertical Multieletrodo (SEVME), para avaliação do arcabouço bidimensional e tridimensional da área e a identificação de zonas de alta resistividade;

(2) Execução de Sondagens a Trado e rastreamento de compostos orgânicos voláteis (VOC).

As seções de GPR 3D se limitaram à porção mais a noroeste da área investigada, local da disposição do resíduo oleoso e possível área fonte da contaminação. As seções de GPR 2D foram adquiridas em uma malha regular com espaçamento entre seções de 10 (dez) metros, com orientações nordeste-sudoeste e noroestesudeste.

Foram adquiridas 123 seções de SEVME nas áreas do projeto, obedecendo ao protocolo tipo Wenner, separadas segundo um malha regular de dez metros e sobrepostas às linhas de aquisição do GPR. A configuração proposta para a área investigada compõese por seções de comprimentos variados, configuração que proporcionou uma cobertura de detalhe, com resolução suficiente para caracterizar desde os substratos mais superficiais aos profundos, permitindo a interpretação do arcabouço geológico local.

A interpretação de GPR foi baseada em conceitos da radar-estratigrafia, procurando-se rastrear terminações de refletores, e desta forma definir compartimentos formados por diferentes materiais, a fim de definir as melhores condições às quais os resíduos oleosos tendem a se depositar e/ou migrar. Aliado a estes parâmetros estratigráficos, procurou-se identificar feições e anomalias próprias do GPR, como boa definição de refletores, que seriam decorrentes de materiais de baixa permissividade relativa e baixa condutividade elétrica, 
que nesse caso seriam correspondentes seqüências arenosas, ou ainda encontrar refletores de baixa qualidade, que seriam produto de materiais de alta permissividade relativa e alta condutividade, como seqüências argilosas ou argilo-arenosas, o que atenuariam a penetração da onda eletromagnética e desta forma comprometeriam a resolução do dado.

A interpretação geofísica da área em estudo foi feita utilizando-se os dados de SEVME e GPR conjuntamente.

\section{Resultados}

A partir da integração dos dados geofísicos foi possível identificar 02 (dois) compartimentos geológicos adjacentes, geneticamente distintos. A seguir segue a descrição dos mesmos:

\section{- Compartimento 01 (Área NW do projeto)}

Localizado a noroeste da área investigada, indicou a existência de anomalias de alta resistividade superficiais, as quais têm continuidade lateral aproximada na direção NW-SE (Figura 1). As sondagens realizadas em algumas destas anomalias identificaram a presença de resíduo oleoso em terreno argilo-arenoso/ areno-argiloso mal selecionado, geneticamente relacionado a uma camada de aterro.

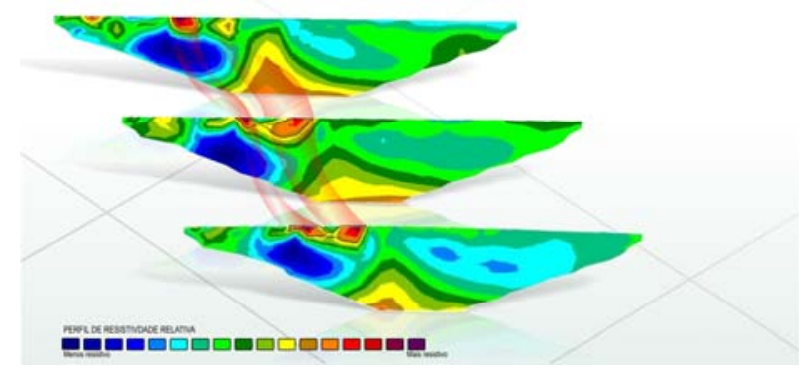

Figura 1: observar configuração tridimensional das regiões de alta resistividade (tonalidades avermelhadas) relativa em baixas profundidades.

Mapeou-se a presença de corpos condutivos (definidos pela tonalidade azulada) situados abaixo das zonas de alta resistividade, identificados pelas sondagens e corroborado por dados de GPR, como solos arenoargilosos saturados em água e compartimentados em segmentos com considerável extensão de direção NWSE e NNW-SSE (Figura 2).

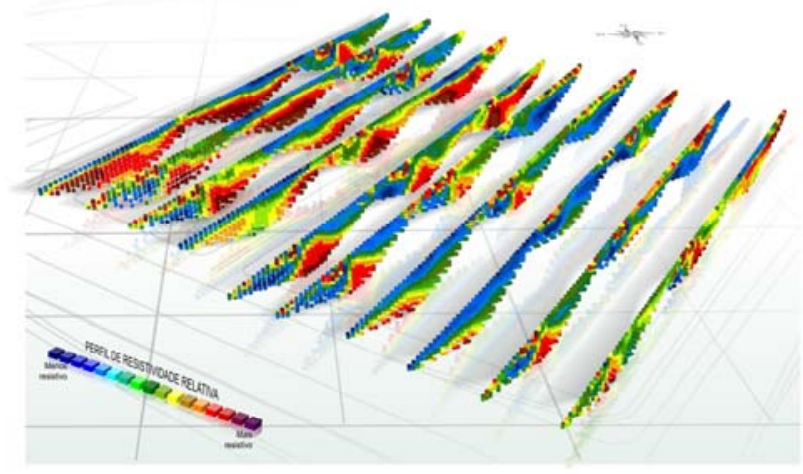

Figura 2: observar configuração tridimensional das regiões de baixa resistividade relativa.

Ainda tendo a SEVME como método orientador, infere-se a presença de corpos resistivos (definidos pela coloração avermelhada) localizados entre dois e quatro metros de profundidade, situados sob a camada saturada conferindo expressiva continuidade areal na região dos diques, especialmente no segmento noroeste e restringindo-se a uma área menor a sudeste (Figura 3).

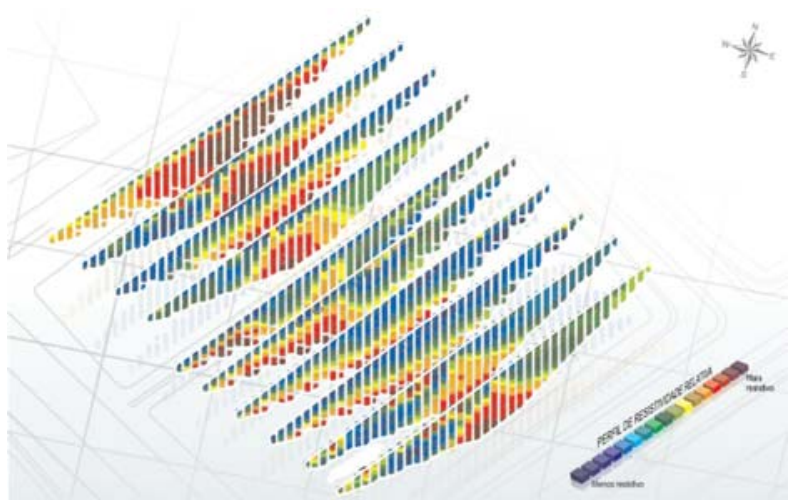

Figura 3: observar configuração tridimensional das reaiões de alta resistividade relativa.

Integrando-se os dados interpretados, individualizaramse seqüências e horizontes (Figura 4), sendo eles:

Aterro: corresponde a um conjunto de refletores regulares horizontais de boa resolução;

Nível d'água: identificado pela mudança de fase no meio que está inserida e pelo alto valor de amplitude, derivada do elevado valor de permissividade relativa e alta condutividade elétrica, quando comparada ao meio que a contém;

Seqüência arenosa saturada: corresponde ao padrão de refletores relativamente regulares, mas que apresentam locais de baixa penetração da onda eletromagnética, e conseqüentemente qualidade de resolução inferior, que estariam associadas a porções saturadas;

Seqüência arenosa não saturada: consiste num padrão de horizontes regulares e de considerável resolução, possivelmente relacionada a um depósito constituído por areia não-saturada 

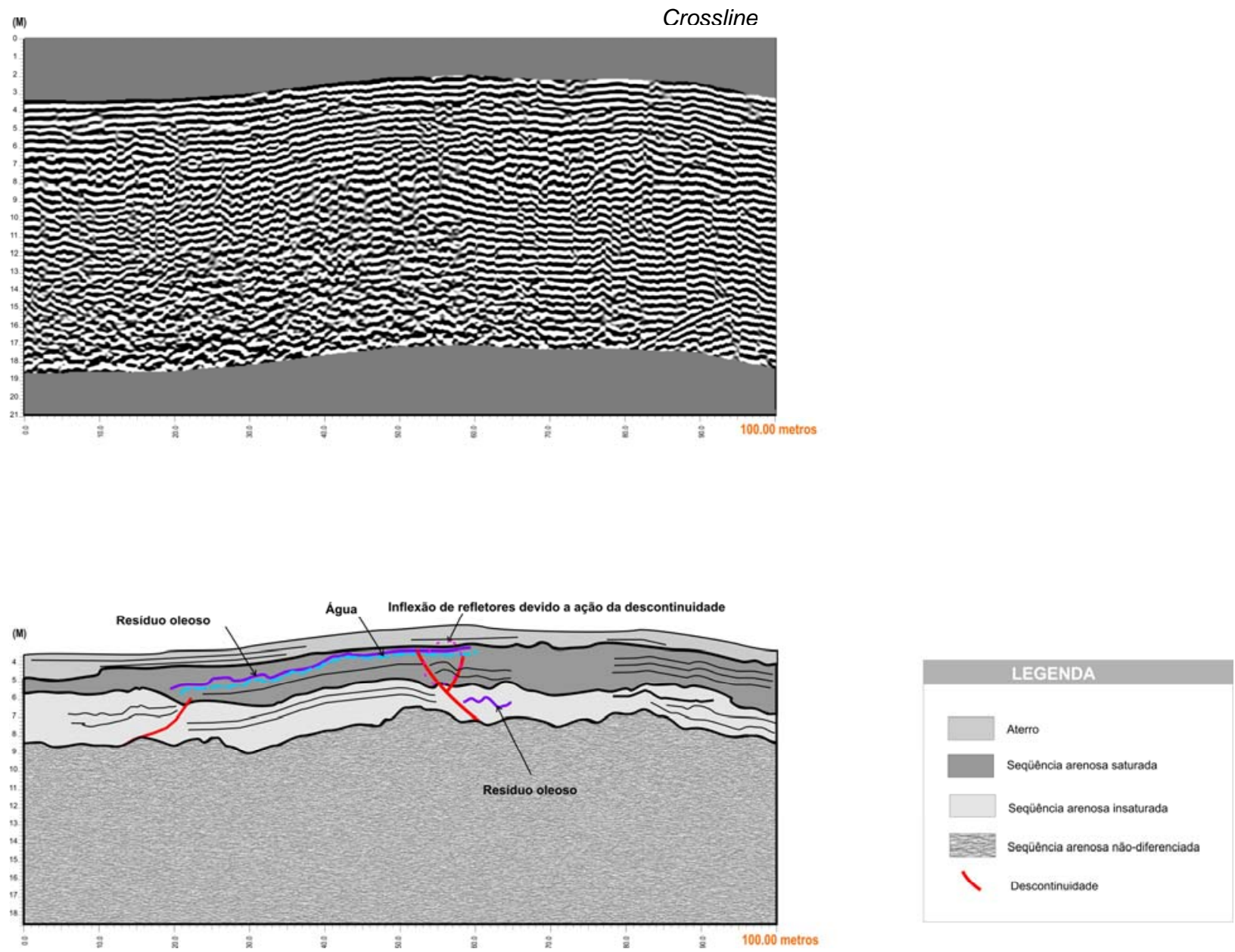

Figura 4: padrões de reflexão, qualidade dos refletores, mudanças de fase e limites das seqüências interpretados nas imagens de GPR.

Embora os dados de SEVME e as sondagens realizadas neste compartimento constatem a presença de contaminante oleoso disseminado na superfície da água, não foi possível identificá-lo claramente no GPR, visto que suas propriedades físicas não definem contrastes de amplitude consideráveis no meio favorável a sua identificação. Desta forma, procura-se balizar a interpretação do mesmo através da mudança de fase produzida por este material no meio e pela continuidade do corpo d'água.

Assim, para melhor definição dos limites do corpo d’água e, portanto, do resíduo oleoso sobrenadante, procurou-se integrar os dados de anomalias resistivas e de GPR já constatadas pelo método direto, a uma análise estatística denominada "Amplitude Principal".
Este método consiste na soma de todos os valores de amplitude na janela de análise, dividindo o seu resultado pelo número total de valores não-nulos.

Através da comparação das imagens geradas pelo cálculo de amplitude nos segmentos sudeste (Figura 5) e noroeste (Figura 6) do compartimento investigado, e do confronto com dados diretos e indiretos, constata-se a validade do método como indicador da provável presença de unidades saturadas em água, nas quais os resíduos oleosos podem ocorrer de forma sobrenadante. 


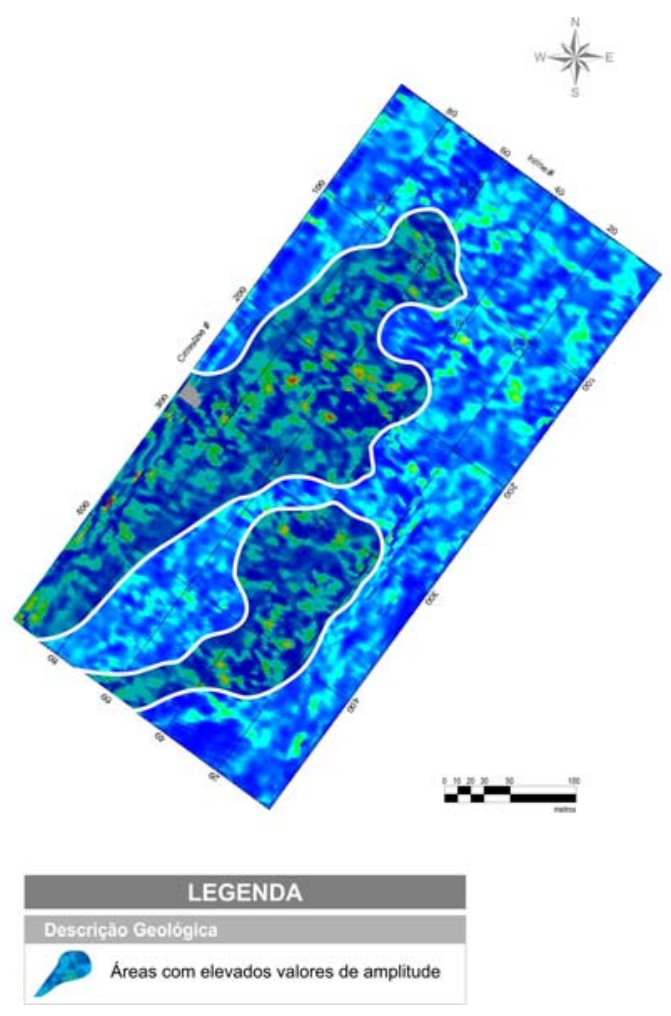

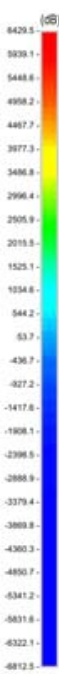

Figura 5: Mapa de amplitude principal relativa identificando áreas saturadas em água na área sudeste do compartimento um.

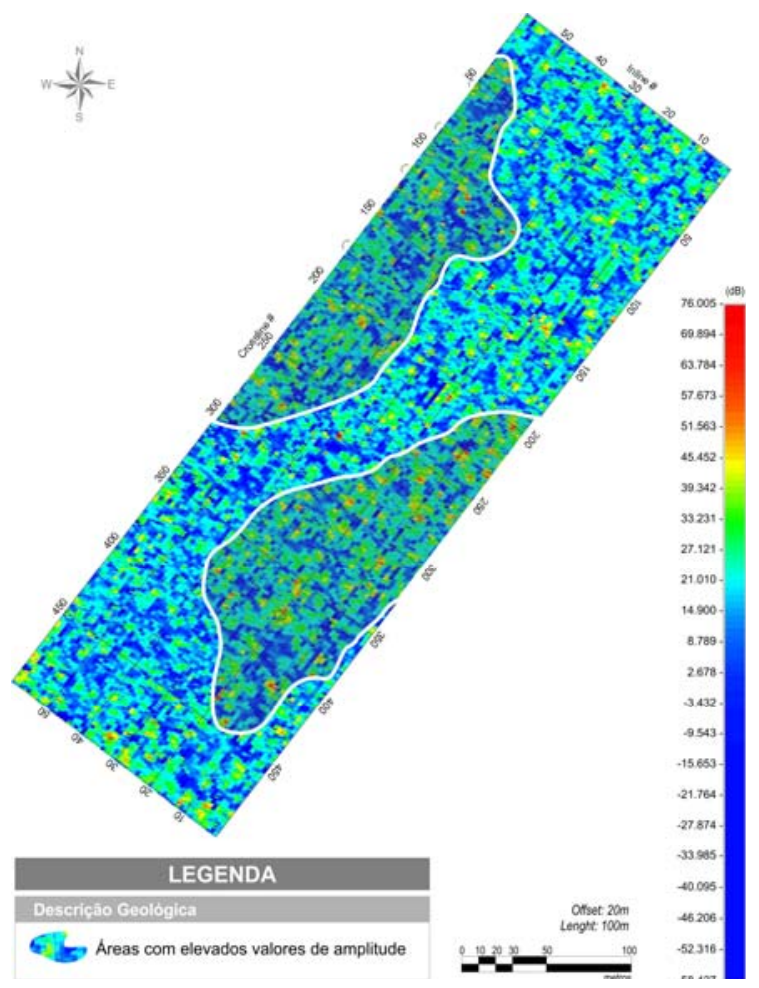

Figura 6: mapa de amplitude principal relativa para o segmento noroeste do compartimento um.

\section{Compartimento 02}

Localizado a sudeste da área investigada. A interpretação dos dados de SEVME e GPR definiu-se cinco seqüências:

Seqüência areno-argilosa recente: Apresenta refletores de boa resolução, em função da natureza do material, com padrões do tipo downlap, característico de ambiente regressivo (Figura 8);

Seqüência areno-argilosa saturada: trata-se de uma camada areno-argilosa saturada em água, caracterizada pelas anomalias de baixa resistividades nas SEVME's, com direção ENE-WSW (Figura 7), e que teria seu depocentro localizado na porção leste da área. Seus refletores apresentam padrões do tipo downlap (Figura 8).

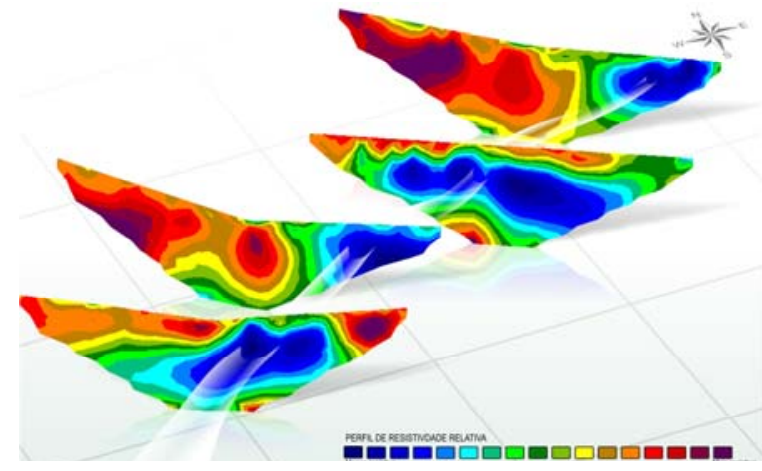

Figura 7: observar seções de SEVME identificadoras da seqüência areno-argilosa saturada.

Seqüência argilo-arenosa: apresenta refletores com padrões típicos de segmentos argilosos, com refletores "caóticos" e de pouca penetração da onda eletromagnética, e conseqüentemente, baixa resolução. Ainda nesta seqüência é possível de se observar padrões de terminação de reflexão do tipo toplap, característico de ambiente transgressivo (Figura 8);

Unidades 1, 2, 3, 4, 5: camadas areno-argilosas que apresentam padrões de terminações de estratos típicos de variações no ciclo hidrológico do rio, com ciclos de curta duração de caráter transgressivos e regressivos (Figura 8);

Topo do embasamento miocênico: corresponde aos refletores contínuos e de amplitude elevada, onde as seqüências anteriores depositam-se discordantemente (Figura 8). 

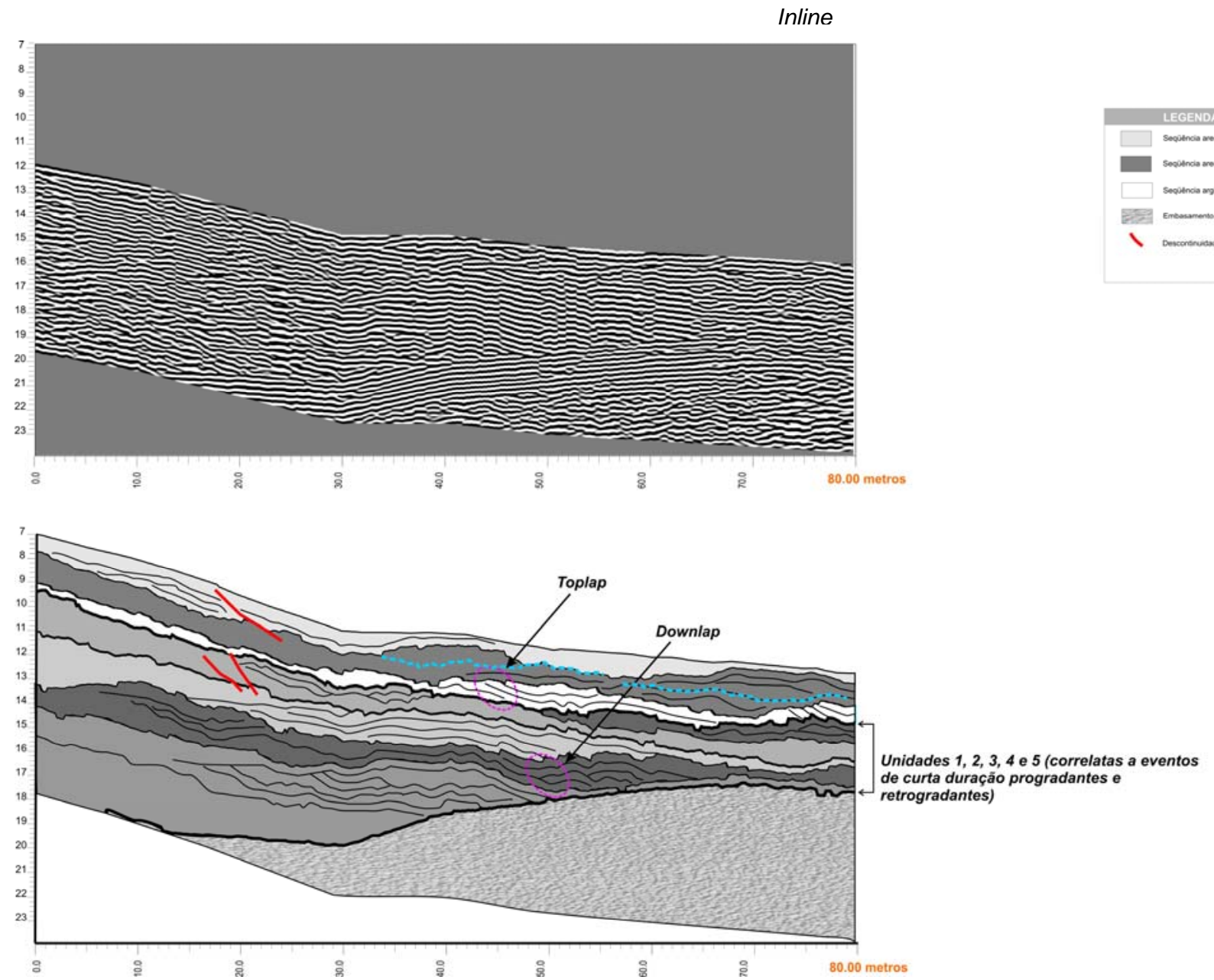

Figura 8: padrões de reflexão, qualidade dos refletores, mudanças de fase e limites das seqüências interpretados nas imagens de GPR para a área da vertente.

\section{Discussão e Conclusões}

Pode-se concluir que os métodos geofísicos aplicados (GPR e SEVME) balizados ao longo por sondagens, mostram-se eficientes, rápidos e seguros na detecção de zonas impactadas, propiciando uma melhor aplicação da base de dados geológicos e ambientais e ampliação do banco de dados local com imagens georeferenciadas.

Permite-se com isso uma racionalização dos trabalhos de sondagem e das análises físico-químicas e, sobretudo, a um menor custo, incorporar um número de interpretações interativas e recursivas que aumentam a precisão da localização das zonas afetadas, o modelamento estimativo de suas espessuras e de sua distribuição espacial, que se fazem necessários na eventual fase de remediação ou monitoramento.
A integração das ferramentas geofísicas apresenta-se como uma das mais precisas metodologias para a avaliação dos possíveis impactos ambientais rasos, causados por acidentes envolvendo hidrocarbonetos e/ou produtos químicos, uma vez que permite visualizar o meio físico e a pluma de contaminantes em subsuperfície, através do delineamento de contrastes físicos e químicos das diversas feições que os constituem.

Através da comparação das imagens geradas pelo cálculo de amplitude nos diques investigados constata-se a validade do método como indicador da provável presença de unidades saturadas em água nas quais os resíduos oleosos podem ocorrer de forma sobrenadante. 


\section{Agradecimentos}

À Brain Tecnologia Ltda. pelo apoio e incentivo e à PETROBRAS pela gentileza na liberação dos dados.

\section{Referências}

Brain Tecnologia, 2006. Nota Técnica - Refinaria Isaac Sabbá (REMAN). Brain Tecnologia Ltda, Belo Horizonte, Brasil. 